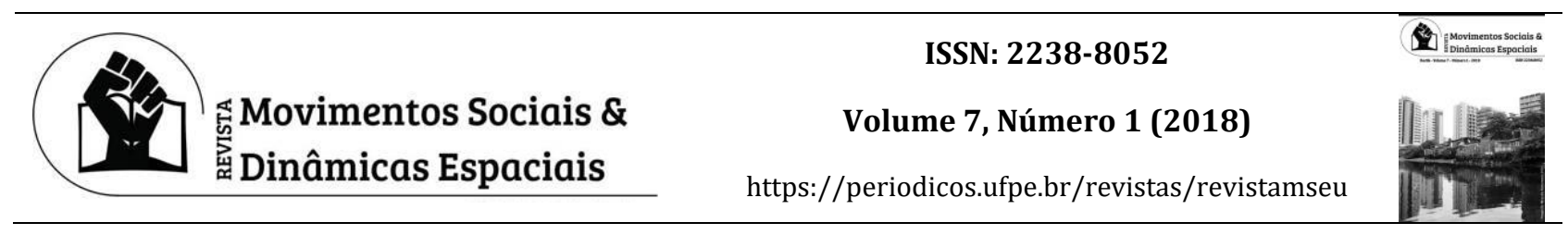

\title{
COOPERATIVISMO E EDUCAÇÃO: REFLEXÕES, POTENCIALIDADES E ESTRATÉGIAS PARA O ENSINO DE GEOGRAFIA
}

\author{
COOPERATIVISM AND EDUCATION: REFLECTIONS, POTENTIALITIES AND STRATEGIES FOR \\ THE GEOGRAPHY TEACHING
}

Armando Peres QUINTAS NETO ${ }^{1}$

Arthur Felipe de Melo TEIXEIRA ${ }^{2}$

Maria do Rozário Azevedo SILVA ${ }^{3}$

Ensaio recebido em 13/05/2018 e aceito em 29/07/2018

Palavras-chave: Cooperativismo;

Ensino de Geografia; Autonomia.

Keywords:

Cooperativism; Geography teaching; Autonomy.

\section{R E S U M O}

Este ensaio é fruto da inquietação de pessoas que refletem sobre o ato de ensinar e buscam formas de fortalecer as qualidades da ciência geográfica enquanto ciência do espaço cidadão. Tendo como fio condutor e pano de fundo uma experiência de sala de aula, ocorrida em 2015 numa escola da rede privada do Recife-PE, desenvolvemos aqui nossas reflexões sobre as perspectivas e aproximações da organização cooperativa em uma sala de aula. Percorrendo um caminho teórico que aborda a autonomia freireana, a governamentalidade foucaultiana e o próprio cooperativismo, buscamos trazer um debate necessário não só às ciências geográficas, mas a todos que pensam a educação em tempos de "Escola sem Partido".

\section{A B S T R A C T}

This essay is the result of the restlessness of people who reflect on the teaching act and pursue ways to strengthenthe geographic science qualities as a science of citizen space. Having as a guideline and background a classroom experience, held in 2015 at a private school in Recife-PE, we have developed our reflections on the perspectives and approaches of the cooperative organization in a classroom. Going through a theoretical approach that addresses freirean theory of autonomy, the foucauldian governmentality and the cooperativism itself, we look for a necessary discussion not only in the geographic sciences, but to all who think about education in times of "School without Party".

\section{INTRODUÇÃo}

Como instigar processos de aprendizagem pautados no cooperativismo e na solidariedade? Essa foi a pergunta que nos motivou quando iniciamos um projeto anual em uma escola da Rede

\footnotetext{
${ }^{1}$ Licenciado e bacharelando em Geografia pela Universidade Federal de Pernambuco - UFPE. Especialista e Análise ambiental pela Universidade Federal do Paraná - UFPR. E-mail: armando-peres@hotmail.com.

2 Graduando em Bacharelado Geografia - UFPE. E-mail: ameloteixeira23@gmail.com.

3 Doutoranda em pedagogia pela Universidade Federal de Pernambuco - UFPE. E-mail: rozario_azevedo@hotmail.com.
} 
Privada da cidade do Recife, no ano de 2015. Esta questão, bem como as potencialidades e sinergias com e para o ensino da geografia motivaram a reflexão que se segue.

A sala de aula é um reflexo da sociedade que vivemos e dos territórios onde estão inseridas. Enquanto professores de geografia, é nosso papel desvelar os fluxos influenciam a configuração do espaço em suas escalas, bem como, analisar de forma crítica as causas e consequências da forma como o espaço é produzido. A sala de aula, enquanto grupo de discentes, é também um microcosmo composto de estrutura social e política, esta estrutura, vias de regras, é debatida através do aspecto psicológico da formação de jovens e em algumas instituições, há setores de psicologia que analisam e intervêm visando fornecer subsídios para o trabalho docente.

O que propomos aqui é lançar luz sobre a viabilidade de utilizar as bases do cooperativismo como uma metodologia ativa em sala de aula, possibilitando aos alunos, espaços de autonomia e protagonismo visando que estes reflitam não só no processo de ensino-aprendizagem, mas também, na forma de organização enquanto grupo classe, vivenciando assim conteúdos extracurriculares, bem como competências e habilidades que estão para além da BNCC (Base Nacional Curricular Comum).

É importante precisar que nosso debate se caracteriza pela ambientação no meio urbano, levamos em consideração a título de construção teórica as experiências no tocante à educação no campo, onde os preceitos do cooperativismo são aplicados com êxito a longa data e de movimentos sociais, que desenvolvem muitas vezes o espírito de unidade e autonomia perante a recusa do Estado de enxergar suas particularidades, porém, na perspectiva em questão, há considerações e adaptações que repousam numa vereda ainda por explorar e que aqui serão levantadas na medida e que foram percebidas.

Estruturaremos nossa explanação inicialmente com uma tentativa de aproximação entre os conceitos de cooperativismo, autonomia e governamentalidade salutares na experiência que tivemos com um grupo classe de alunos do $9^{\circ}$ ano e utilizando esta experiencia como plano de fundo para nossa argumentação.

\section{BASES TEÓRICAS}

\subsection{Cooperativismo}

As cooperativas são vistas atualmente como uma forma de promoção do desenvolvimento econômico e social, uma cooperativa de qualquer ramo pode resgatar a cidadania através da participação democrática, da liberdade e da autonomia, sendo considerado uma das formas mais avanças de organização da sociedade civil, SIEBERT (2013).

Para a Aliança Cooperativa Internacional, essa se define da seguinte forma "é uma associação autônoma de pessoas, unidas voluntariamente, para atender às suas necessidades e aspirações 
econômicas, sociais e culturais comuns, através de uma empresa coletiva e democraticamente controlada", segundo a mesma entidade as cooperativas são pautadas nos seguintes princípios "1o adesão voluntária e livre; $2^{\circ}$ gestão democrática pelos cooperados; $3^{\circ}$ participação econômica dos cooperados; 4ํatonomia e independência das cooperativas; $5^{0}$ educação, formação e informação; $6^{0}$ Interoperação; $7^{0}$ interesse pela comunidade."

No texto de Frantz (2001) o autor define cooperação como,

[...] um processo social, embasado em relações associativas, na interação humana, pela qual um grupo de pessoas busca encontrar respostas e soluções para seus problemas comuns, realizar objetivos comuns, busca produzir resultados, através de empreendimentos coletivos com interesses comuns. (FRANTZ, 2001, p. 242)

Ressaltamos aqui o caráter social do cooperativismo, esta visão é a forma que consideramos mais adequada aos fins pedagógicos pretendidos, pois, ainda segundo Frantz (2001), existe uma clara relação entre cooperativismo e educação, na formação de uma cooperativa existe a necessidade da comunicação de interesses, de objetivos e práticas, sobre os quais têm que se tratar em grupo, tal troca de saberes favorece o aprendizado, já na prática educativa, processo complexo das relações sociais encontra-se a cooperação da troca de saberes.

Nossa experiência com a formação de uma cooperativa em sala de aula se deu com um projeto batizado pelos estudantes de "COOP8B" consistiu em formar uma cooperativa de solidariedade, onde elementos do cooperativismo como: assembleias, votação, decisão conjunta, debate, objetivos comuns, igualdade entre membros, seriam introduzidos inicialmente nas vivências das aulas de geografia, objetivando trazê-las para o cotidiano dos estudantes tornando assim a solidariedade e a cooperação orgânicas as atitudes do grupo.

Esta vivência e prática pedagógica adveio da nossa observação da turma em questão, onde a liberdade e o poder proposto aos estudantes passavam sempre pela tutela de algum docente e que quando favorecidos, o poder de decisão era mantido por uma minoria, diante disso, buscamos em Kropotkin (2009) a inspiração para elaborar a estratégia de ação.

Neste trabalho ele aborda como tema principal a ajuda mútua, caráter este inerente aos organismos vivos. Entre as formas de ajuda mútua está inscrito o cooperativismo, que, não se atem ao economicismo, através das práticas em diferentes setores, artes, música, educação. Figurando como uma das principais formas de organização e emancipação social, segundo o autor. Vale a pena reforça que a cooperativa pode ser utilizada enquanto metodologia para alcançar a ajuda mútua. Seu valor pode ser atestado quando o mesmo autor aborda casos de mineiros e marinheiros que arriscaram a vida para salvar companheiro de associação, contrapondo esses eventos a afogamentos ocorridos diante de multidões em grandes centros urbanos, em suas palavras,

"Entre os mineiros e os marinheiros, graças as suas ocupações comuns e ao contato cotidiano entre si, cria-se um sentimento de reciprocidade e os perigos que os rodeiam educam neles a coragem e o talento audaz. Nas cidades, pelo contrário, a ausência de interesses comuns educa a indiferença; e a coragem e o talento, que 
raramente encontram aplicação, desaparecem ou tomam outra aplicação" (KROPOTKIN, 2009 p. 216.)

É importante salientar que o processo teve seus percalços, o que mais nos chamou atenção foi a dificuldade dos alunos lidarem com processos de autonomia e a necessidade de mando. É, no mínimo, contraditório que estudantes propusessem práticas onde pudessem decidir, opinar e encaminhar e trouxessem em seguida, o não cumprimento de tais encaminhamentos por falta de quem os "ordenassem" a ação:

Eu não ajudei muito. Critiquei bastante o projeto e tentei detonar várias iniciativas, Mas eu estava nervosa, não tinha ideia de como trabalhar, pois, nunca tivemos um trabalho nesse formato e com esse nível de autonomia.(Estudante)

[...] não tive iniciativa, não sabia o que fazer com tanta liberdade que foi me dada. Mas quando recebia instruções, tentava ao menos fazer. (Estudante)

As falas foram colhidas através de uma autoavaliação escrita que foi aplicada como fechamento do projeto. Elas exaltam outro elemento que se tornou relevante para nossa argumentação que é o conceito de autonomia.

\subsection{Autonomia}

Em seu trabalho de 1996, Pedagogia da autonomia, Freire aborda inúmeros verbetes relacionados à tarefa de educar e tudo que essa possa exigir, mas, em nenhum momento ele aborda diretamente o verbete que dá título a esta obra. A partir de nossa leitura percebemos que a autonomia incorre e é organicamente ligada ao bem educar, segundo o autor e para tal, o educador deve estar ciente do que a tarefa de educar exige e de como essas reflexões devem estar inclusas nas práticas educativas, para que este perceba, a necessidade de busca da sua própria autonomia enquanto pessoa e educador.

Inúmeros fragmentos nos fazem crer em tal afirmação, "Gosto de ser gente porque, inacabado, sei que sou um ser condicionado, mas, consciente do inacabamento, sei que posso ir mais além dele" (FREIRE, 1996, p. 53) e falando de liberdade o autor aborda diretamente autonomia,

\footnotetext{
Ninguém é sujeito da autonomia de ninguém. Por outro lado, ninguém amadurece de repente, aos 25 anos. Agente vai amadurecendo todo dia, ou não. A autonomia, enquanto amadurecimento do ser para si, é processo, é vir a ser. Não ocorre em data marcada. É nesse sentido que uma pedagogia da autonomia deve estar centrada em experiências estimuladoras da decisão e da responsabilidade, vale dizer, em experiências respeitosas da liberdade. (FREIRE, 1996, p. 107)
}

Acreditamos no elo que existe entre as afirmações do autor e de se pensar práticas educativas que permitam que essa autonomia floresça, tanto para o professor quanto para os educandos, acreditamos também que essa autonomia se desenvolve a partir de inúmeras decisões em diferentes 
escalas, e que, as práticas cooperativas podem vir a ser instrumentos de extraordinária valia na forma de se pensar a inserção diária deste exercício.

Buscando um diálogo entre autores sobre este conceito, laçamos mão do texto de ROSA (2014) no qual em um capítulo a autora debate autonomia sob a óptica do construtivismo Piagetiano, familiarizando-nos com relação aos dois conceitos relacionados a juízo moral, validos tanto para crianças quanto para adultos. A heteronomia "[...] se refere à postura de obediência a uma lei ou regra exterior ao sujeito que lhe obriga a orientar-se pelo que é "certo" ou "justo" pelos representantes da moral social." (ROSA,2014, p.67). O segundo conceito é o de autonomia "se associa a capacidade do indivíduo de aderir às normas sociais pelo reconhecimento racional e livre quanto à sua pertinência e justeza" (idem). A autora ainda distingue que o primeiro resulta da mera "obediência" e do respeito unilateral, já o segundo, do respeito mútuo e da relação de cooperação.

Acreditamos que tais reflexões devem estar presentes quando buscamos práticas que se propõe críticas e emancipatórias, principalmente no que se refere à nossa prática docente. Não há como falar de uma sociedade mais justa e igualitária enquanto pairamos na frente de jovens e crianças como sumidades que tem seu poder emanando de uma caderneta burocrática.

No caso em questão, assembleias eram feitas semanalmente durante as aulas de geografia, no decorrer do projeto, foi-se percebendo uma crescente apatia com relação aos assuntos da cooperativa, os alunos haviam elegido três eixos em que desenvolveriam atividades acadêmicas e práticas, objetivando o dia de culminância do projeto, para tal, eram debatidas metas semanais para os eixos, todos se comprometeram a executar a atividade do eixo de sua escolha, com os descumprimentos por parte da maioria a apatia começou a se destilar entre os alunos que, excetuando os que nem se pronunciavam em assembleia, praticaram um discurso de aversão aos caminhos eleitos por eles, passaram buscar culpados entre os membros e que em linhas gerais queriam a dissolução da cooperativa.

As reações direcionadas aos professores foram as mais notáveis, inicialmente com uma postura de revolta e rebeldia, pois, atestavam que os professores não os "ajudavam" e era essa a causa dos insucessos, tal comportamento durou até a aproximação da data limite, quando os estudantes passaram a ter uma postura suplicante de autoridade e mando por parte dos professores, o que até o final se traduziu em facilitação de formas e ideias que eram trazidas pelos estudantes e em oficinas que relacionavam os conteúdos curriculares as atividades do projeto.

A reflexão sobre a postura dos estudantes nos leva ao terceiro ponto de nossa argumentação.

\subsection{Governamentalidade}

O que nos liga ao conceito de Governamentalidade de Foucault é sua dimensão política uma vez que para o autor “A análise da governamentalidade [...] implica que 'tudo é político'. [...] A política não é 
nada mais, nada menos que o que nasce com a resistência à governamentalidade, a primeira sublevação, o primeiro enfrentamento". (Foucault, 2008, p. 287)

Tal conceito foi desenvolvido por Foucault como definição do ato de estatização das ações de governar. Em várias obras, como Microfísica do Poder (1992) e Segurança, Território e População (2008), ele explica como a arte de governar foi inventada e gradualmente construída, passando de uma ação baseada na relação entre príncipe (soberano) e principado (súditos), para uma outra ação, pautada numa racionalidade técnica e ideológica de gestão e gerenciamento entre governante (Estado) e governados (sociedade). Nesse sentido, Foucault fala sobre os tipos de governo que se cruzam no interior do Estado e se tornaram a base das teorias da arte de governar, quais sejam: o governo de si mesmo (referente à moral), o governo da família (referente à economia) e o governo do Estado (referente à política).

Essa situação nos remete também às reflexões de Foucault sobre a governamentalidade pautada num tipo de poder específico, o poder pastoral. Este, tendo por objetivo a conduta dos homens, preocupa-se em conduzi-los.

[...] correlativamente a isso, apareceram movimentos tão específicos quanto esse poder pastoral, movimentos específicos que são resistências, insubmissões, algo que poderíamos chamar de revoltas específicas de conduta, aqui também deixando à palavra 'conduta' toda sua ambigüidade. São movimentos que tem como objetivo outra conduta, isto é: querer ser conduzido de outro modo por outros condutores e por outros pastores, para outros objetivos e para outras formas de salvação, por meio de outros procedimentos e de outros métodos. São movimentos que também procuram, eventualmente em todo caso, escapar da conduta dos outros, que procuram definir para cada um a maneira de se conduzir. (FOUCAULT, 2008, p. 256-257)

Nessa perspectiva, o sujeito "inexiste" ele é aquilo que pode ser feito dele posto que a subjetividade e as relações de poder são indissociáveis. Esta é a base das tecnologias da subjetividade, nas quais a subjetividade é um efeito e não uma origem: ocorre uma modelagem e não um sujeito formandose autonomamente em suas escolhas. MARSHALL (1994), afirma que para Foucault "[...] a compreensão que temos de nós mesmos como pessoas capazes de efetuar escolhas livres e autônomas é, ela própria, uma construção que nos permite ser governados, tanto individual quanto coletivamente." (p. 22)

Este aspecto de cuidado subjacente ao poder pastoral foi visível na fala dos estudantes participantes do projeto. As relações que foram percebidas com esta prática nos levaram aprofundar nossa postura no sentido subverter e dissolver esta necessidade de mando dentro de sala de aula e buscar na relação professor-aluno uma horizontalidade real, levando os educandos a perceber como as relações de poder são inerentes e hegemônicos em todos os aspectos de nossas vidas, levando-os assim a refletir sobre as possibilidades de encarar os papéis de professor e de aluno. 


\section{CONCLUSÕES}

Esperamos que com este ensaio possamos instigar a reflexão dos professores de geografia para a importância não só conceitual que a matéria tem na formação de cidadãos, bem como chamar atenção para o papel e possibilidades que podem ser aplicadas objetivando uma educação comprometida com uma emancipação real.

Em seu texto de 1905, Reclus (2014) tratando da importância do ensino da Geografia, cita o fato do Governo Russo ter proibido o ensino desta disciplina em Universidades do Estado, isso nos idos de 1884. Reproduziu o seguinte trecho do discurso oficial "É uma vã Ciência, que apresenta ao aluno fatos estranhos às tradições nacionais e desvia-o do caminho da obediência em que deve procurar manter-se todo o ensino sério" (RECLUS, 2014, p.32). Acreditamos que, a Ciência Geográfica nos dias atuais contém o mesmo poder libertador que assustava o Governo Russo do século passado, pois essa "demonstra a unidade perfeita do grande domínio terrestre e o absurdo das fronteiras" (RECLUS, 2014, p.32). Acreditamos ainda, que no mundo pós-modernos as forças coercitivas são muito mais hegemônicas do que um Estado autoritário.

A metodologia cooperativa é uma possibilidade de formar cidadãos que compreendem o mundo pelas lentes que a Geografia pode lhes conceder, não pelos conteúdos previstos, mas pela possibilidade de construir suas próprias análises das dinâmicas espaciais que os cercam independente da escala e de vivenciar experiências que propiciam compreensão sobre autonomia e democracia.

\section{REFERÊNCIAS}

FRANTZ, Walter. Educação e cooperação: práticas que se relacionam. Sociologias, Porto Alegre, n.6, Jul/Dez. 2001. Disponível em:<http://tinyurlcom/h8sydnp >

FOUCAULT, Michel. A hermenêutica do sujeito.

São Paulo: Editora Martins Fontes, 2010. . O governo de si e dos outros. São Paulo:

Editora Martins Fontes, 2010. - Microfísica do Poder. Rio de Janeiro: Graal,1992.

. Segurança, território e população. São

Paulo: Martins Fontes, 2008.

FREIRE, Paulo. Pedagogia da autonomia: saberes necessários à prática educativa. $30^{\circ}$ edição. São Paulo: Paz e Terra, 1996.

Pedagogia do oprimido. Rio de Janeiro: Paz e Terra, 1987.

KROPOTKIN, Piotr. Ajuda Mútua: um fator de evolução. São Sebastião: Senhora editora,
2009.

MARSHALL, James. Governamentalidade e Educação Liberal. In: SILVA, Tomaz Tadeu (Org.). O sujeito da Educação: Estudos Foucaultianos. Petrópolis: Vozes, 1994.

ROSA, S. S. da. Pinóquio Educador: ensinar e aprender na escola contemporânea. São Paulo: Cortez editora, 2014.

RECLUS, E. KROPOTKIN, P. Escritos sobre educação e Geografia. São Paulo: Biblioteca Terra Livre, 2014.

SIEBERT, M. Educação cooperativista: conceitos, reflexões e experiência da Blucredi. Disponível em: $<$ http://tinyurl.com/h4kxalb>. Acesso em: dez. 2017. 